
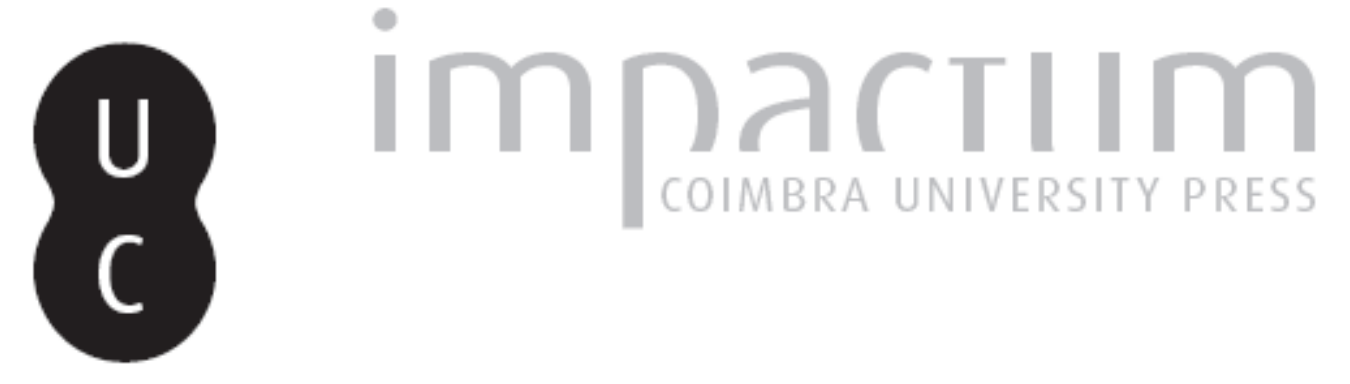
Portabilidade, evanescências e rubricas: discussões em torno da literatura digital na
sala de aula

\author{
Autor(es): $\quad$ Corrêa, Alamir Aquino
}

Publicado por: Centro de Literatura Portuguesa; Imprensa da Universidade de Coimbra

URL persistente:

URI:http://hdl.handle.net/10316.2/39105

DOI:

DOI:http://dx.doi.org/10.14195/2182-8830_4-2_11

Accessed : $\quad$ 26-Apr-2023 11:04:33

A navegação consulta e descarregamento dos títulos inseridos nas Bibliotecas Digitais UC Digitalis, UC Pombalina e UC Impactum, pressupõem a aceitação plena e sem reservas dos Termos e Condições de Uso destas Bibliotecas Digitais, disponíveis em https://digitalis.uc.pt/pt-pt/termos.

Conforme exposto nos referidos Termos e Condições de Uso, o descarregamento de títulos de acesso restrito requer uma licença válida de autorização devendo o utilizador aceder ao(s) documento(s) a partir de um endereço de IP da instituição detentora da supramencionada licença.

Ao utilizador é apenas permitido o descarregamento para uso pessoal, pelo que o emprego do(s) título(s) descarregado(s) para outro fim, designadamente comercial, carece de autorização do respetivo autor ou editor da obra.

Na medida em que todas as obras da UC Digitalis se encontram protegidas pelo Código do Direito de Autor e Direitos Conexos e demais legislação aplicável, toda a cópia, parcial ou total, deste documento, nos casos em que é legalmente admitida, deverá conter ou fazer-se acompanhar por este aviso.

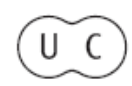



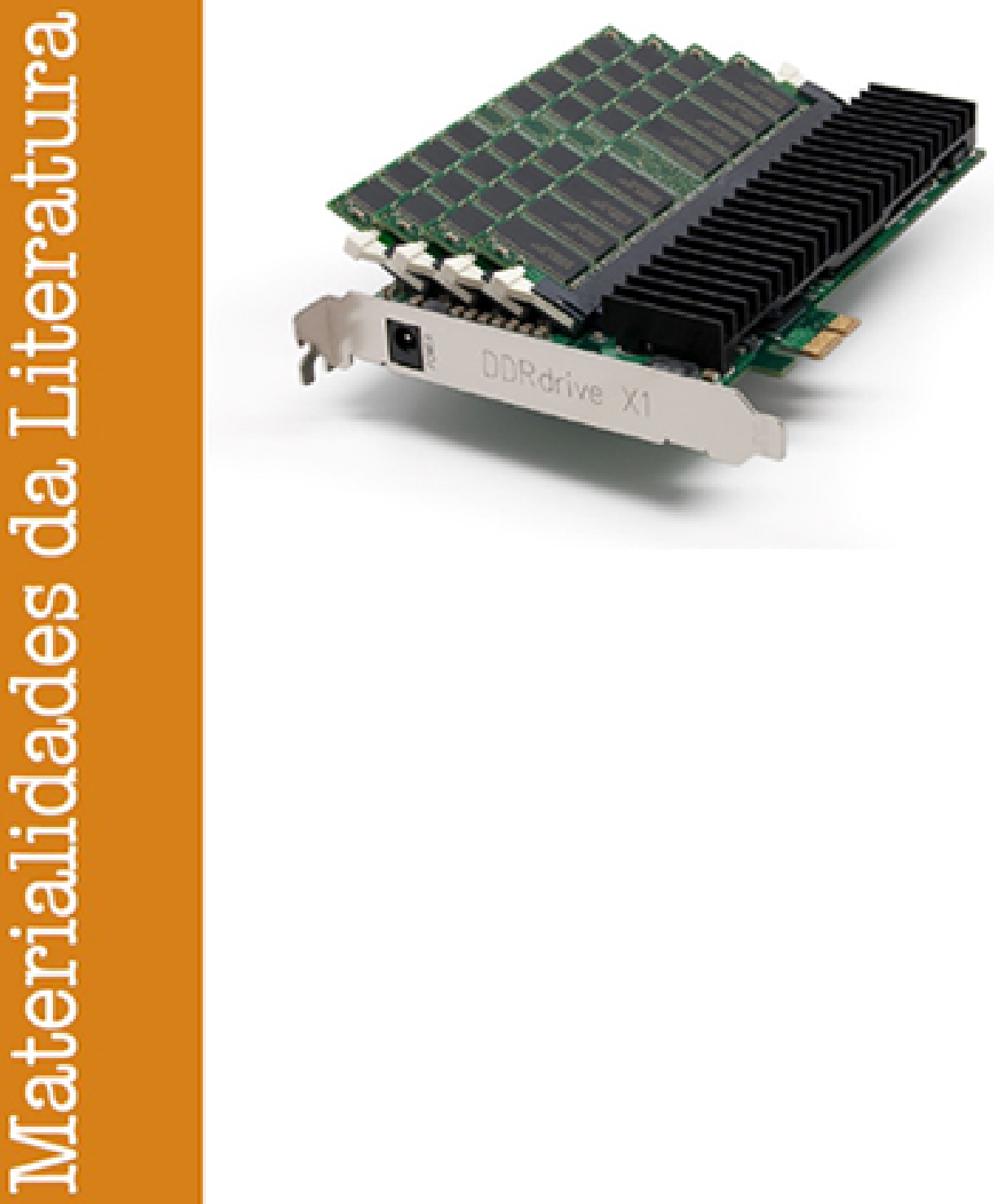

Vol. 4.2 (2016) ISSN 2182-8830

'Estudos Literários Digitais 2'

Manuel Portela e António Rito Silva (orgs.) 


\title{
Portabilidade, Evanescências e Rubricas: Discussões em torno da Literatura Digital na Sala de Aula ALAMIR AQUino CORRÊA
}

\author{
Universidade Estadual de Londrina
}

\begin{abstract}
Resumo
Esse texto trata de três aspectos que afetam a tentativa de abordagem em sala de aula do texto literário criado em ambiente digital, observando suas relações com a formação pedagógica de futuros professores. A integridade do objeto e sua possível recepção, denominada de portabilidade, será caracterizada pelo enfrentamento direto do texto pelo fruidor e a sua difícil ou improvável reprodutibilidade em sala de aula enquanto experiência estética. No caso da evanescência, tanto o acesso, enquanto experiência estética, quanto o estudo, como crítica, se tornam problemáticos diante de obstáculos como georrefenciamento, direito autoral, transitoriedade do objeto e obsolescência de software e hardware. Por último, as rubricas ou os mecanismos norteadores da experiência de leitura não só a organizam, mas também impõem desde antes os limites da percepção do objeto literário. Palavras-chave: literatura digital na sala de aula; formação pedagógica para o ensino de literatura digital; portabilidade; evanescência; rubricas.
\end{abstract}

\section{Abstract}

This paper addresses three issues affecting the attempt to teach digital literary texts in the classroom by observing their implications for pedagogical practice in the preparation of future teachers. The integrity of the digital object and its reception, which I call portability, is discussed through the modes of engagement with the text and its unlikely or difficult reproducibility as an aesthetic experience in the classroom. In the case of evanescence, both the access to the aesthetic experience and the study as criticism become problematic due to obstacles like geo-referencing, copyright issues, object transience, and obsolescence of software and hardware. Finally, the guidelines for the reading experience not only organize but also impose a priori limits to the perception of the literary object. Keywords: digital literature in the classroom; pedagogy for the teaching of digital literature; portability; evanescence; guidelines.

$\mathbf{N}$ o contexto das humanidades digitais, especialmente da literatura "digital", há uma perplexidade agigantada por dois modos provavelmente complementares entre si. Há a novidade do sistema digital para a maioria dos usuários, tanto receptores quanto supridores de ferramentas de leitura, análise e compreensão das obras literárias; esses são em maioria imigrantes digitais, a se apresentarem como intérpretes canônicos, logo sagrados detentores das verdades sobre a literatura, talvez sem consciência de seu papel instrumentalizador ou nas palavras de Robert Scholes: "Our 
job is not to produce 'readings' for our students but to give them the tools for producing their own” (1985: 24). E há a angústia diante do próprio sistema, a lidar com particularidades (diferenças entre literatura digitalizada e literatura em ambiente digital), circunstâncias técnicas (disponibilidade de instrumental adequado para o ensino ao lado da noção de seu alto custo e que deve ser protegido pelas instâncias administrativo-pedagógicas), e nuanças políticas.

Entre essas últimas, há o acesso e a organização do material respeitando o direito autoral, por vezes díspar em geoposicionamento, e em razão de condições socioeconômicas, inclusos os mecanismos de controle, a lembrar dos casos do Metallica versus Napster e do Pirate Bay. O acesso livre resultaria em maior criatividade, informação e conhecimento, mas as limitações ao processo criativo, nas aplicações com base em um sistema proprietário, acabam por gerar desequilíbrios e ruas de mão única, por gerarem objetos artísticos que só podem ser fruídos mediante pagamento de licenças ou de compra de suportes autônomos (como o CD-ROM e DVD ou os tablets), reiterando a divisão entre quem tem acesso e quem não tem - mesmo que conectado ao mundo digital. Esse foi o caso de Agrippa: The Book of the Dead de William Gibson, publicado em 1992. O poema era vendido em um floppy disk e se autodestruía após uma única leitura. Começou sendo vendido a 450 dólares e chegou a 2,000. No entanto, o código do livro foi quebrado pouco tempo depois e o texto foi divulgado na internet ${ }^{1}$. Entretanto, em razão da ausência de mercado (pelo menos aparentemente) para a literatura digital e as facilidades de publicação na web, o acesso livre predomina, ainda que não resulte em maior quantidade visível de autores e produtos.

As sociedades estabelecem proibições para evitar desvios do ordenamento ou rupturas do direito autoral, ou como exercício de soberania nacional. Néstor García Canclini, em Culturas Hibridas (25), alerta ser a contemporaneidade pautada pela disseminação democrática da informação por uma via e recolha ou acumulação de poder por outra. O Estado e as corporações transnacionais partilham, idealmente, da noção libertária da inclusão de todos, no mundo pretensamente globalizado; mas há um "tecno-apartheid", por seu tom segregacionista onde as desigualdades se tornam maiores (García Canclini, 2004: 189-190), especialmente pelo monolinguismo do material técnico maiormente disponível em língua inglesa.

Talvez essa angústia se desfaça futuramente, a replicar as crises do surgimento de novas formas de arte como o cinema e o vídeo (moldados enquanto espetáculo e experiência estética individual e/ou coletiva), e das previsões apocalípticas sobre o desaparecimento do professor no ensino a distância ou a presença maligna do vídeo cassete em sala de aula, a tornar precária a interação entre professores e alunos. Os problemas surgem das imensas dúvidas sobre o lugar da literatura em espaços criativo, receptivo/fruitivo e

${ }^{1}$ http:/ / agrippa.english.ucsb.edu/category/the-book-subcategories/the-poem. 
instrumentalizante (caso da escola, particularmente aquela de nível superior), que incluem algumas discussões sobre o fazer literário em meio digital. Nas manifestações poemáticas, a tradição crítico-teórica marca a questão taxionômica a enumerar um leque de opções: poesia digital, poesia eletrônica, ciberpoesia, poesia hipermediática, poesia hipertextual, ou tecnopoesia (Corrêa, 2016), e as relações entre a literatura produzida no suporte impresso e aquela no suporte digital. Isso é importante nas discussões provocativas como a diferença entre textos analógicos e digitais (Lavagnino, 2008) ou a ausência de novidades no mundo digital explicitada por Funkhouser (2008): "Contemporary digital poetry essentially refines earlier types of production and disseminates works to a wider audience via the network." Entretanto, pululam outras inquietações sobre o trabalho em sala de aula, mormente pela ausência de tradição crítico-pedagógica e por certo temor ou desconforto diante dos novos objetos, ainda que possa haver neles uma qualidade similar aos textos impressos, em termos de sonoridades, pictorialidades e interrelações, lembrando aqui não só da ousadia de Mallarmé e dos dadaístas, mas também das experimentações (poesia concreta, poesia visual, videopoemas e grafismos multimediáticos das instalações).

Assim, certas questões se tornam prementes, com as necessárias abordagens do assunto na formação de novos críticos/professores: que materialidades são prevalentes no objeto literário digital? A intermedialidade, enquanto expressão resultante da interação e interdependência de diferentes m[ídias, contribui para a construção de novos significados ou é apenas circunstância como as descrições enquanto técnica com ares de cientificidade na narrativa do período realista? A multimedialidade da produção poética digital enseja que tipos de experimentalismos e de proposições de significados, no conjunto de textos teórico-explicativos que costumeiramente os acompanham? Até que ponto a experimentação, quer pela remediação quer pela intermedialidade, pode provocar respostas críticas constituidoras de valor? A interatividade, sempre resultado do planejamento computacional, abre novas possibilidades de significação? O grafismo (visualidade e tipografia) se torna elemento constitutivo da fruição da obra poética digital?

Nessa provocação, tratarei de três aspectos que têm me afetado na tentativa de abordagem, em sala de aula, do texto literário criado em ambiente digital. Há neles a constante do lócus, quer dizer, as relações do objeto artístico com a prática pedagógica instrumentalizadora de futuros professores. Por primeiro, quero discutir a noção de integridade do objeto e sua possível recepção, denominada aqui de portabilidade. Por segundo, será necessário tratar da evanescência, problema não exclusivo do mundo digital, mas que o afeta sobremaneira, em razão de possível ou provável desaparecimento ou, ainda, da dificuldade de armazenamento e disponibilização, ainda que um paradoxo em ambiente digital em face de seu menor custo de armazenamento em redundância. Por fim, discutirei as rubricas, na acepção das indicações que ocorrem em textos para cinema, teatro, televisão e música, como norma- 
tização da experiência estética, ou seja, os mecanismos norteadores da leitura e da experiência estética, muitas vezes manifestos estéticos, que não só organizam a leitura, mas impõem desde antes os limites da percepção do objeto literário.

Esse conjunto de problemas é um dos próximos desafios do ensino de literatura, pelo progressivo aumento quantitativo de textos multimediáticos, cada vez mais elaborados tecnicamente e com uma qualidade particular - a criação literária coletiva - talvez verdadeiramente nova. A produção artística resultante de vários saberes, habilidades e competências exigiria um novo leitor ou fruidor? Mais sério ainda, por exigir vários criadores para um mesmo objeto, a se aproximar da produção do filme, do vídeo e de outros espetáculos coletivos, esse novo objeto tensiona menos o sistema de canonização pela produção hipoteticamente menor de obras, ainda que as novas tecnologias permitam cada vez mais o domínio do computador? Se por um lado a tecnologia tem permitido a ampliação de acesso a fontes e a revisão do cânone escrito pela construção de bancos de dados (Earhart, 2012), restará ainda, por outro, verificar efetivamente se a produção literária digital é passível de processos de canonização pela crítica (por exemplo, Hartling, 2005; Rettberg, 2013; Pressman e Swanson, 2013; Price e Siemens, 2013; Pressman, 2014) e pela instrumentalização de leitores e novos professores.

\section{Ensino: natividades e imigrações digitais}

Para tratar desse desafio é necessário compreender em que situação se encontra a escola, diante das novidades tecnológicas disponibilizadas em maior escala nos últimos vinte anos. Apesar de vários planos educativos, postulados por governos nem sempre conscientes das circunstâncias específicas de uma sala de aula, só recentemente passou a haver uma problematização maior do ensino em ambiente digital como angústias que incluem a imensidade de novas fontes de discussão tanto impressas quanto digitais. Há ou não uma nova sala de aula (Knewton)? Que novos alunos são estes (Prensky, 2001: 1)? Como lidar com esses textos/mídias novos e diferentes ou competências e competências novas (Bolter, 2007: 108)? Qual a materialidade da produção literária digital (Giampá, 2010)? É possível continuarmos a ser os professores que éramos e/ou sabemos que professores queremos ser (Prensky, 2010: 5)? Sabemos formar e treinar alunos para o futuro (Woodall, 2014: 124)? Há um novo admirável mundo novo (Tweedie, 2015)? Essa consciência resulta em alguma forma diferente de agir (Payne, 2013)?

Para Prensky (2010: 3), a educação deve ter significado imediato e a tecnologia nova é um direito percebido como inalienável, conquanto muitos ainda resistam aos avanços, com ar de enfado ou de prepotência, talvez a mascarar os meneios e receios de uma imigração digital. Assim, há dois sujeitos: o nativo e o imigrante digitais, distinção feita por Prensky, usada amiúde 
em órgãos de porte internacional, como a UNESCO e seu Policy Brief de setembro de 2011, apesar das discussões a respeito do alcance e da significação de tal proposta (Smith, 2013). Apesar disso, está claro que a escola se divide entre formados em ambiente digital e aqueles sem a experiência digital (interessantemente detendo o poder regulador da escola). E com certeza, há aqueles sem acesso ao mundo escrito, digital ou impresso.

Além das preocupações sobre os imigrantes digitais, o nativo digital pode não ter sido formado exclusivamente nesse mundo, se tomado o conceito como absoluto. Ainda, o indivíduo dominante das tecnologias digitais vê-se capaz de aumentar seus horizontes progressivamente, diante da realidade e não pela relevância ditada por entes canonizados e entronizados (Prensky, 2010: 4), ainda que essa perspectiva careça de maior respaldo (Bennett, Maton e Kervin, 2008). Os imigrantes digitais ainda são os responsáveis pela escola, colonizadores de um novo mundo cujas permissões e desejos de funcionamento estão motivados por interesses a mais das vezes incompatíveis. Se por um lado a escola define categoricamente o que é relevante, mesmo que o aluno nunca tenha necessidade de saber os nomes dos rios afluentes da margem direita do Amazonas ou a capital da Zâmbia, por outro, o estudante se interessa por aquilo que tornará certa tarefa mais fácil (passar de nível de um jogo) ou mais rápida (chegar ao concerto de rock no fim de semana).

Marc Prensky afirma que a transformação educacional está em todo lugar menos na escola (2010: 1); mesmo que afirmação apocalíptica, realmente muito pouco tem sido feito no sentido de transformar o tipo de ensino, especialmente o universitário (Jones e Shao, 2011). O dever de casa (ou "depois da aula") se tornou mais importante que as atividades desenvolvidas em sala de aula ou já era assim desde antes? Além de prevalente o modelo magister dixit (o professor-conhecimento a ditar normas e saberes), há um enorme golfo de informações que mal dele se sabe ou se pode acessar (caso da deep web visível ${ }^{2}$ a partir de navegadores específicos ${ }^{3}$ ). Nas salas de aula em rede, onde deve prevalecer o modelo do compartilhamento, a dificuldade de controle do fluxo de informações é mais do que tácita, pois é praticamente impossível limitar o que se faz com o compartilhamento e os interesses individual e grupal. A bem da verdade, perdeu-se a hegemonia da condução da aprendizagem, no sentido de seu norteamento controlado, exceto feito aos paradigmáticos exames de competências, habilidades e fatos (nem sempre todos exigidos). A reação à escola autoritária e autenticadora é natural; cada vez mais se percebe seu esvaziamento, mesmo em sistemas pautados pela obrigatoriedade da escola média e, mais importante no caso brasileiro, na escola superior enquanto degrau social a alavancar grupos com tendência de

\footnotetext{
${ }^{2}$ http://zqktlwi4fecvo6ri.onion/wiki/index.php/Main_Page (em caso de acesso, não clicar em qualquer linque, por precaução).

${ }^{3}$ https://www.torproject.org/.
} 
exclusão (Baggi e Lopes, 2011: 362.). As licenciaturas e bacharelados estão em crise em vários países e as humanidades se percebem alijadas do processo decisório institucional, a tartamudear muxoxos e lágrimas esquivas. A conclusão é uma só: não há mais o gênio, o carisma e a liturgia da atividade pedagógica centrada no professor, diante dos novos instrumentos a balizar o contato com o conhecimento.

Ainda que crença a testar, a escola deixou de atrair o estudante, por sua dificuldade de compreender a mudança de comportamento das novas gerações e por um comodismo ou resistência a inovações. O bordão de que o conhecimento adquirido na escola jamais será roubado do indivíduo perdeu o seu brilho; há outro universo de conhecimento antes indisponível que se espalha e aumenta a cada minuto via computadores, tablets e smartphones. Essa condição da tecnologia na sala de aula acaba por dar suporte à proposta básica da pedagogia de Marc Prensky: o partilhamento ou parceria; por contraste, nas redes sociais o compartilhamento ou o retuíte é ferramental por vezes danoso e incontrolável (Ronson, 2015), mas é socialmente eficaz por sua exponenciação, muito além do que se supunha (Attiah, 2015). Por certo viés de contemporização, Prensky transfere ao estudante a tarefa de socialização da tecnologia e cabe ao professor treinar/indicar/guiar o uso dessa tecnologia para o aprendizado "efetivo". A seguir, há de se discutir a questão pertinente à área de estudos literários, principalmente como provocação de outros problemas (a materialidade da literatura digital, seguramente marcada pela intermedialidade, o acesso e a crítica canônica).

\section{A materialidade da literatura digital}

Como questão primeira, ao se tratar da literatura digital - ou outras denominações como "literatura eletrônica" (Hayles, 2008) - enquanto objeto estudado em sala de aula, surge a diferença em relação à literatura digitalizada, aquela publicada em papel e levada ao ambiente digital. Mas, mesmo que o suporte final seja em papel, muito acaba passando pelo processamento digital, que deixa suas marcas no livro impresso (Hayles, 2008: 43). Para aqueles interessados no processo criativo, há novos problemas, vez que raramente se poderá ter acesso aos "digituscritos" (as versões originais e transformadas/alteradas pelos autores) e o registro de edição poderá se perder, por conta da volatilidade dos meios ou sua natureza fluídica (Hayles, 2008: 39-40). A construção do texto, por conta do processamento textual, recebe outro verniz, talvez a partir da sua reorganização por listas de palavras ou outro tipo de busca. O autor pode reorganizar sua produção, em símile com as edições revisadas de recolha como antologias ou "a melhor produção de X", buscando induzir o leitor a percebê-la como entende ser mais legível ou inteligível e não como foi concebida inicialmente, como é o caso da obra Não de Augusto de Campos 
(2003), organizada em animogramas, infopoemas e morfogramas (Kirchof, 2013: 132).

Há hoje uma literatura produzida em ambiente digital, com autores espalhados pelo mundo (a problematizar a noção de pertença a uma literatura nacional), a juntar em seus objetos percepções da literatura que talvez problematizem o seu próprio estrato - aquela circunstância percebida como literariedade (a mais das vezes diáfana, ou seja, sem um elemento formal evidente), além da discussão sobre os diferentes gêneros advindos das experimentações e soluções digitais. Dessa forma, há de se pensar o que torna literário um objeto criado com essa intenção em ambiente digital. Hayles pergunta se tal criação (eletrônica) pode ser literária ao fim das contas; se a publicação aberta a todos sem qualquer crivo não resultaria apenas em bobagens sem valor; se esse material em verdade não é inferior à literatura impressa; e qual será o futuro da escrita a partir desse contexto de uma cultura digital (2008: 2). Outros de seus posicionamentos podem ser percebidos como indagação acerca da função da arte digital na transformação da literatura nesse espaço ou qual é o aspecto essencial dessa forma artística. Afinal, as experimentações artísticas no mundo digital fazem convergir diferentes proposições de escrita, leitura e crítica por conta de sua multimodalidade (Hayles, 2008: 22).

Um elemento essencial, a mostrar a diferença em relação à literatura "tradicional", é a qualidade compositiva a partir do uso de uma ou mais linguagens de programação, pela intertextualidade ou hiperlincagem (planejada e limitada pelo autor), algo que obriga nova e diferente abordagem da obra de arte, a realizar uma crítica literária e um ensino cujo ferramental ainda está por fazer. Matthew Kirschenbaum (2008) caracterizou tal situação complexa, em Mechanisms: new media and the forensic imagination, como materialidade forense - a lidar com as qualidades encontráveis no processamento físico dos dados pelo computador (por exemplo, diferenças de voltagem na escrita e na leitura de bits nas placas giratórias dos discos duros) e aquela formal - com o ato de leitura a partir de uma lógica compositiva, a envolver em vários níveis as atividades realizadas pelo usuário (visualização da tela/janela e de ícones a clicar) e aquelas imperceptíveis (as negociações entre sistema operacional e aplicativos e entre objetos lógicos e conceituais).

Há cada vez mais a consciência de que o texto literário adquire essa qualidade pela condicionante social (Juvan, 2000), mesmo que se defenda contrariamente a existência de uma qualidade formal (caso de parte do Formalismo Russo, a Escola de Chicago, a Nova Crítica e a Imanência do texto, principalmente em Staiger e Kayser). Se a heteroglossia aventada por Bakhtin (2002: 85) caracteriza as variações tão próprias das divergências sociais e os diferentes estratos literários e não-literários, é por ela que se pode entender os processos de canonização e as tentativas de sua ampliação e/ou revisão. A literatura pode assumir diferentes versões de sua qualidade, especialmente em momentos de busca de maior inclusão social, como se está a viver a partir 
dos estudos culturais, uma vez que a noção da emoção estética provocada pelo texto parece ter deixado de ser importante pela ênfase identitária entre grupo e o material proposto como obra de arte. Essa atitude tem marcado boa parte da indústria cultural, em particular aquela vinculada ao mundo acadêmico, funcionando como defesa ideológica da visibilidade de grupos matizados por qualidades específicas (gênero, etnia, distribuição urbana, faixa etária, renda, etc).

A literariedade ainda continua a ser ensinada como algo genial, talvez divino - como se percebe nas listas de autores recomendados nos exames de ingresso universitário no Brasil, nos certames literários anuais ou na proposição de histórias literárias fundadas em estilos de época, cânones que enfatizam o patrimônio a partir da noção de uma qualidade estética ou respeitável pela tradição -, a adensar a condição do ser humano na produção de arte (estabelecida e reconhecida a priori pela escola, local de efetiva canonização). Dessa maneira, uma obra se faz literária e canônica, enquanto o sistema a classifica por esse viés. Não é de outra sorte a percepção distinta de Paulo Coelho no Brasil quando comparado com sua recepção em França e em Espanha (exemplos são seus prêmios: Chevalier de L'Ordre National de La Legion d'Honneur concedida pelo governo francês, a Medalla de Oro outorgada pela Galiza e o prêmio Crystal Award concedido pelo Foro Económico Mundial), ou do tratamento dado a Jorge Amado nos cursos de Letras brasileiros pela força da crítica universitária oriunda das universidades paulistas (Corrêa, 2012).

Essa mesma escola se mostra ainda avessa ao que é levado ao meio digital ou nele produzido; vários colegas bradam publicamente que obra boa é aquela impressa em papel. Por exemplo, uma revista brasileira de excelência na área de Letras exige em suas chamadas de 2015 a submissão de artigos por e-mail, gravados em CD e impressos em papel, enviados por correio comum, a evidenciar o valor maior e fixo no material "concreto e não virtual" (pela noção de sua possível evanescência). Só recentemente, a partir de 2006, as teses e dissertações no Brasil, antes a acumular poeira nas estantes das bibliotecas e raramente encontrando espaço editorial, começaram a ser depositadas e lidas em sua versão PDF. Revistas que se atreveram a existir somente em ambiente digital, desde sua primeira edição, demoraram muito para ter o seu valor reconhecido e ainda são olhadas muitas vezes com desdém, por não imprimirem seus textos, a ponto de haver estranheza pelo acesso livre e gratuito a suas edições. Esse comportamento caracteriza muito ainda das proposições de ensino, como se o material canônico tivesse absoluta prioridade sobre aquele digital; a mesma escola que faz isso advoga a liberdade da arte moderna como a maior e melhor modificação possível (como a pintura abstrata ou a poesia concreta). Por esse ângulo, só poderá haver maior presença da literatura digital em sala de aula quando houver uma maior receptividade pela escola para essa produção. 
A possível história da produção literária digital, pelo menos aquela predominante nos Estados Unidos, tem sido dividida em dois momentos: o período clássico (a imitar o chamado cinema clássico) a partir de Afternoon a Story (1987) de Michael Joyce até Patchwork Girl (1995) de Shelley Jackson, quando prevaleceu um sistema autoral hipertextual chamado StorySpace; e o período contemporâneo, desde então até que surja um novo patamar ou proposição (Hayles, 2008: 4-7). Anote-se entretanto haver outras proposições a enfatizar a hipermedialidade da poesia concreta (desde a década de 1950) ou, na proposição de Funkhouser (2007; 2012), uma pré-história da poesia digital ou os recentes usos de Flash, Shockwave, Java e Javascript, por exemplo, para produção, apropriação de distribuição de poesia digital. Já se trata da questão dos gêneros (como ficção interativa, arte gerativa ou os jogos), especialmente com o advento da internet em larga escala (os jogos interativos, multimodais e multiusuários demonstram a sua força comercial e a manutenção do clima de novidade, ao sabor do suspense de novos níveis ou novas tramas, logo versões renovadas e/ou ampliadas) e das nuanças da hiperlincagem ou da multimedialidade, no que se convencionou denominar de Web 2.0, onde a interação se funda principalmente a partir do usuário enquanto produtor de conteúdo, como se vê no Facebook, no Instagram ou no Youtube. As problemáticas acerca do poder do autor e do leitor, como levantou Landow (2006: 321), são observadas no âmbito da crítica a lidar com a permanência e a importância da literatura digital no contexto geral do mercado produtor e receptor de bens digitais (Yoo, 2007: 22-24). No geral, pode-se caracterizar assim essa produção: (a) ela se motiva como literária e digital, por usar de elementos além da palavra, caracterizando-se por um hibridismo a reunir a palavra e outras linguagens mediáticas (som, texto animado, arte gráfica computacional e estrutura de rede); (b) é heterogênea, experimental e de vanguarda (Collins, 2010: 6); e (c) a canonização desse material fica adjacente ao posicionamento de seus autores no mundo acadêmico. Talvez a produção literária digital tenha o mesmo nível de marginalidade do fenômeno da geração mimeógrafo, uma vez que tem seu valor registrado aqui e ali, principalmente por um grupo que se mostra aberto também a experimentações pedagógicas e criativas, mas ainda não se faz canônica pela resistência dos departamentos de estudos literários nas universidades, como relata Kirchof (2013), a partir de exemplos de relatos de colegas na Espanha, Inglaterra e Eslovênia.

\section{Das dificuldades}

O ponto de partida é a proposta de levar obras literárias digitais para a sala de aula, observadas desde antes as questões específicas sobre esse conjunto de obras e eventuais características e peculiaridades estéticas. Os principais obstáculos, além das preocupações já elencadas sobre a sua materialidade inter- 
medial em ambiente escolar, são a portabilidade, a evanescência e as rubricas. Antes de discuti-los, anoto a existência de Reading Moving Letters, coletânea de ensaios organizada por Simanowski, Schäffer e Gendolla (2010). Da leitura dos capítulos sobre ensino de literatura digital, saltam interessantes argumentos como: (a) a relação combativa da literatura digital com o conjunto canônico, este já a exigir enorme esforço didático; (b) a condição ambígua dessa produção digital a navegar entre literatura, artes visuais e performance; (c) a interdisciplinaridade necessária para tratar de objeto complexo e híbrido; (d) ainda o maior espaço para as chamadas disciplinas "normais", com tradição de especialidade, ou seja, aquelas fundadas em estilos de época ou no cânone de grandes autores; (e) a dificuldade do estabelecimento de uma experiência mais comum diante desse objeto, por sua recursividade e multilinearidade; e (f) não há fortuna crítica de maior porte, fragilizando a avaliação e o ensino, a obrigar maior subjetividade e atividade por parte do alunado, talvez um material complexo demais para vários deles.

Isso posto, há de se tratar da portabilidade como a noção de integridade do objeto e sua possível recepção. Essa nuança se caracteriza pelo enfrentamento direto do texto pelo fruidor, observando as particularidades especiais do contexto socioeconômico, especialmente em comunidades onde, embora haja e seja importante a conectividade digital, há uma suspeita ou reserva geral acerca do mundo digital enquanto detentor de valor estético ou artístico, uma vez que se mostra desvinculado ou desvirtuado do suporte clássico do papel impresso. Assim, torna-se importante qualificar e descrever as maneiras de interação do fruidor com o objeto literário digital, incluindo aí os eventuais descritores como impeditivos da fruição - quer dizer, as proposições teóricas e/ou explicativas que acompanham e precedem os objetos literários digitais, bem como problematizar os mecanismos de reprodutibilidade, se é que existem, da experiência estética, mormente nos casos das instalações e/ou produções multimediáticas como Palavrador de Chico Marinho, Volta ao Fim e O Cosmonauta de Wilton Azevedo e Alckmar Luiz dos Santos.

No contexto do material literário digital, pensando na sala de aula, é de se lembrar das várias instâncias a preocupar e provocar autores e leitores, como faz Alckmar Luiz dos Santos em vários momentos de seu Leitura de nós (2008), é necessário estar consciente da necessidade de um letramento visual (Stokes, 2001) para lidar com esse complexo objeto, e há dificuldades consideráveis para acesso, por limitações várias - incluindo tanto componentes de hipercolonialismo (Sanz, 2013), enquanto condições que privilegiam o acesso a fontes em determinados países tornando seus pesquisadores quase que donos imperiais do conhecimento, quanto de execução e arquivamento (Hayles, 2008: 14-15; 40-41). Apesar dessas dificuldades e cuidados, se tomado um objeto para estudo, a despeito da discussão sobre a tradição canônica, ou seja, considerando que ele existe, logo deve ser também abordado em sala de aula, é de se buscar soluções para algumas circunstâncias preocupantes. 
A sua execução é ou não viável em ambiente escolar em razão de eventual interatividade ou de se ter acesso apenas ao seu registro, como um vídeo a reproduzir o evento em que atores/autores executaram a obra em algum espaço. Há necessidade de um aparato crítico aumentado, além daquele de base textual normalmente usado na formação dos cursos de Letras, ampliando para professores atuantes e estudantes de graduação os níveis de percepção de um objeto que transita por várias linguagens, inclusive e especialmente computacionais, na sua criação, execução e recepção, em face do contexto geral da familiaridade de usuários em relação à arte, como ausência ou impossibilidade de percepção estética ou apeirokalia (Corrêa, 2014).

Tanto a leitura, enquanto experiência estética, quanto o estudo, como recepção e crítica, se tornam problemáticos diante de alguns obstáculos como o georreferenciamento de acesso conforme o direito autoral, a transitoriedade do objeto vinculado à contínua manutenção financeira da hospedagem e do domínio (quando o acesso é em linha), e a construção interna do objeto em linguagens e aplicativos ineficazes em novos computadores. Essas condições acabam por afetar tanto autores quanto usufruidores, como um grave contratempo para a canonização do material e o uso dele no ensino, exigindo propostas tentativas de sua organização e preservação.

Aliás, não é de outro tom os projetos de concentração ou organização seletiva da produção literária digital em centros universitários de referência. Por um lado, busca-se catalogar e propor uma taxonomia crítica da literatura digital, como se percebe nos diretórios Electronic Literature Organization ELO (coleção de obras, descritores e palavras-chave) ${ }^{4}$ e Electronic Literature as a Model of Creativity and Innovation in Practice - ELMCIP (banco de dados que reúne informações sobre autores, obras, crítica, eventos organizações, editores, recursos pedagógicos, coleções de pesquisa, bancos de dados e arquivos). Por outro, é de se apontar a coleta de obras, de maneira a disponibilizá-las em um só local (como uma biblioteca ou antologia especializada); citem-se, como exemplo, a ELMCIP Anthology of European Electronic Literature, organizada por Maria Engberg, Talan Memmott e David Prater, e os três volumes da Electronic Literature Collection, ${ }^{6}$ organizados por vários autores e críticos de literatura digital. Há ainda os bancos de dados que replicam a literatura impressa, tornando-a mais acessível, sendo que sua construção depende muito das limitações do direito autoral, como é o caso do Google Books ou da Biblioteca de Literaturas de Língua Portuguesa sediada e construída pelo NUPILL da Universidade Federal de Santa Catarina. ${ }^{7}$ Essa produção digital, por paradoxo, sofre de uma "doença crônica", ainda que se diga que "caiu na rede, é impossível apagar"; quer dizer, talvez mais que o

\footnotetext{
4 http:/ / directory.eliterature.org/.

${ }^{5}$ http://anthology.elmcip.net/.

${ }^{6} \mathrm{http}: / /$ collection.eliterature.org/.

7 http://www.literaturabrasileira.ufsc.br/.
} 
livro impresso, prezado por muitos por sua longevidade e ubiquidade física, o objeto digital sofre por uma evanescência inerente a sua própria condição.

A rápida evolução dos computadores pessoais e, depois, a migração em maior escala para smartphones e tablets (inclusos os e-readers), tanto no processamento e armazenamento, quanto na sua execução gráfica, tornou a interação entre humanos e produtos digitais cada vez mais prazerosa, em termos de usabilidade, conforto visual e instantaneidade de execução. Esses avanços obrigam inclusive, por conta de novos algoritmos de busca, a revisão de sites para que possam ser lidos pelos modelos móveis. Por contraste, aplicativos ou execuções de códigos, como se fazia em Basic ou em Assembler na década de 1980, perderam seu apelo e precisam de ajustes para seu uso, por meio de máquinas virtuais (VM), como é o caso dos jogos da ATARI. No que se refere aos objetos artísticos, a interatividade planejada como um jogo de tentativa e erro (em geral) se torna quase risível por conta de sua defasagem tecnológica em relação ao hardware. Esse apagamento está em símile com o desenvolvimento do cinema e da televisão, cabendo ao usuário fruir de tais objetos com desconforto pela ausência de novidade e de estranhamento.

Há, entretanto, outros complicadores como o desaparecimento de softwares, alguns defuntos pela competição própria do mercado. É aquilo que se chamou de legacy ou legado - nem sempre tão fácil de acessar/usar; pior, alguns objetos podem ter perdido a possibilidade de sua execução, por não haver mais o suporte necessário para sua reapropriação (tanto em termos de software quanto em termos de hardware) ou, se há, o seu custo é por demais elevado. A extinção programada e efetivada por fases de certas conjunturas, como o orkut e as animações em Quicktime, gera situações até esdrúxulas. Pesquisas sobre tais objetos não podem ser repetidas, dando aos estudiosos um poder inimaginável - o de uma confiabilidade pela inexistência dos objetos eventualmente eliminados por decisão corporativa, venda de softwares por companhias que preferem eliminá-los, desinteresse em razão de seu envelhecimento tecnológico ou mesmo fatos fortuitos, como a perda de direito de uso de domínios de sítios. É como se estivéssemos a lidar com civilizações ou culturas extintas - a construir uma teoria sobre o nada. Rastros desses materiais sugerem o nascimento de uma arqueologia cibernética a lidar com pedras de Rosetta quase contemporâneas. Ou seja, iniciativas de construção de acervos de literatura digital (incluindo os apps literários ${ }^{8}$ ) são mais do que obrigatórias, incluindo as condições para sua execução, como acontece no projeto "Pathfinders: Documenting the Experience of Early Digital Literature" iniciado em 2012 e coordenado por Dene Grigar e Stuart Moulthrop. ${ }^{9}$

8 http:/ / www.dazeddigital.com/artsandculture/article/19888/1/ten-literary-apps-tomake-writing-more-than-words-on-a-page.

${ }_{9}^{9}$ http://dtc-wsuv.org/wp/pathfinders/description/. 
Por fim, as rubricas são de fundamental importância para a explicação de textos digitais em sala de aula. Normas balizadoras da experiência estética na tradição da "performance" ou construção de objetos artísticos no cinema, no teatro, na televisão e na música, nelas fica evidente a organização tutorial, quando em tese deveria ser o mundo digital em tais produções um baluarte da liberdade receptora. Ou seja, em vários casos, além das limitações técnicas de repetibilidade de alguns objetos literários, como se viu em parte da produção de Eduardo Kac, há também um fator preponderante de impedimento da interação; a recepção do objeto digital se dá a partir do norteamento estético, logo manual de uso, de apresentações, prefácios e, até mesmo, palestras, talvez tornar mais importante a autoria ou a crítica do que a própria obra. Essa circunstância particular, no espaço da metainformação, acaba por condicionar a compreensão e a fruição da obra digital, pois exige mecanismos e preparos pedagógicos maiores; não é mais simplesmente o apontamento de características formais de um poema ou de um romance ou das qualidades estilísticas de época de um conjunto de obras. Há de se perceber um nível maior de complexidade técnica, incluindo aí até mesmo uma ponderação estética sobre o ato criativo (e colaborativo em alguns casos), para o qual a universidade ainda não prepara, quer por resistência ao mundo digital quer por falta de uma compreensão dos novos objetos artísticos (ou literários) produzidos em meio digital.

\section{Das possiveis soluções para o ensino da literatura digital}

No corpo de produções literárias digitais, reconhecendo que já há várias disciplinas ofertadas em universidades mais ousadas, no sentido de serem mais abertas a novidades (remontando o seu início aos anos $90^{10}$ ), com bons programas de aulas (ou syllabus ${ }^{11}$ ), faz-se aqui uma proposta de ordenamento dessas rubricas. A intenção primeira de uma taxonomia de tais rubricas é ponderar sobre os mecanismos usados até aqui, propositivos de uma diminuição da complexidade da ética digital, a respeitar a obra em termos de sua usabilidade, o direito autoral e a fruição estética, para o usuário pouco ou nada familiarizado com esse admirável mundo novo - quer dizer, é um mundo de maravilhas, a lembrar aqui do romance de Emílio Salgari (Le meraviglie del duemila, 1907), vendidas, apresentadas, organizadas como objetos maiores, talvez quase sagrados desde o seu nascimento, o novo fogo de Prometeu. Percebem-se algumas posturas na apresentação, organização e divulgação de tais produções, apresentadas a seguir.

$10 \mathrm{http} / / /$ www.eastgate.com/Courses.html.

${ }^{11}$ Ver, por exemplo, "Electronic Literature" por Leonardo Flores (2012), na Universidade de Bergen (Noruega) - http://dikult203.tumblr.com/syllabus, e "Hypertext and Electronic Literature" por Jesse Stommel (2015), na Marylhurst University (EUA) - http://www.jessestommel.com/hypertext/syllabus.html. 


\section{(a) incompreensões sobre o caráter digital}

A novidade do meio digital, ainda que já haja razoável preocupação com o seu ensino há cerca de um quarto de século, prevalece até mesmo entre aqueles que buscam fazer literatura digital. Sem desmerecer o trabalho e a intenção, aponta-se para as dificuldades de compreensão até mesmo do uso do meio digital. Há um sítio brasileiro, Literatura Digital, apresentado como movimento, cujo ideal é, por "um viés acadêmico e outro criativo, divulga[r] e fomenta[r] tanto a reflexão e a discussão teórica acerca dos novos gêneros que surgem quanto produzindo, divulgando e apoiando projetos de literatura digital"; tem à frente Anna Mello, Marcelo Spalding e Maurem Kayna. ${ }^{12}$ Em uma das páginas desse sítio, há a seguinte nota: “A literatura digital é uma obra literária feita especialmente para mídias digitais, impossível de ser publicada em papel."13 A página "Minicontos de ouvir", projeto organizado por Letícia Schwartz e Marcelo Spalding (2013), é um conjunto de arquivos em MP3, como alternativa de leitura para "todos aqueles que, por qualquer motivo, precisam ler sem ver", ${ }^{14}$ contendo somente textos verbais lidos, a mimetizar o que as instituições voltadas para cegos vêm fazendo há décadas. Já o projeto dos "Minicontos coloridos" de Marcelo Spalding (com data de 2012 na página "Literatura brasileira para web" e lançado em janeiro de 2013) não ultrapassa a barreira de uma aleatoriedade de composição textual e gráfica, usando um formulário ("miniconto.php") pela "escolha" de cores primárias aditivas (RGB, em pequenas gradações) ${ }^{15}$ que resulta em um "miniconto" sob fundo "escolhido" pelo usuário.

\section{(b) remediação}

Bolter e Grusin (1999) propuseram o conceito de remediação como processo de reorganização ou melhoramento de um objeto, pela absorção de uma versão por outra em outro meio. Para vários sítios, ${ }^{16}$ a "frankensteinalidade" proposta por Mary Shelley se mostra remediada por Patchwork Girl de Shelley Jackson. Talvez esse tipo de rubrica se configure muito mais como verdadeira compreensão de um gênero literário digital. De outra maneira, os exemplos propostos aqui se mostram não como plágio ou mote e glosa, processos clássicos de pertença, tampouco como releituras tão próprias do caráter intertextual, mas e precisamente como outorga de uma outra versão: interessantemente, os novos objetos remediados se mostram como diretamente vinculados e provocados pela versão anterior.

\footnotetext{
12 http:/ / www.literaturadigital.com.br/?pg=25009.

${ }^{13}$ http://www.literaturadigital.com.br/minicontoscoloridos/literaturadigital.html.

14 http://www.literaturadigital.com.br/minicontosdeouvir/.

15 http://www.literaturadigital.com.br/minicontoscoloridos/.

${ }^{16}$ Exemplo: http://litinawiredworld.wikia.com/wiki/Remediation.
} 
A obra The Library of Babel (2015), ${ }^{17}$ de Jonathan Basile, é uma remediação do conto de Jorge Luis Borges. Está fundada na combinação das 23 letras do alfabeto (obviamente sem os diacríticos, por exemplo, o "ç"), a permitir "all possible pages of 3200 characters, about $10^{4677}$ books" - o impensável livro infinito. Sua estrutura básica, se é que isso é possível, se mostra como três possibilidades de vórtice: "folhear" (browse enquanto procedimento aleatório), "buscar" (search) e "aleatório" (random). A título de exemplo, buscou-se no sítio $^{18}$ a palavra remediation, para demonstrar que ela existe como existe também qualquer outra palavra a ter testada a sua existência, desde que se observe a circunstância combinatória e reiterativa das 23 letras. A busca produz quatro tipos de resultados: combinação perfeita, caracteres aleatórios (ou letras), palavras em inglês aleatórias e como título. Também ocorre estar essa obra organizada por uma conceituação/definição, ${ }^{19}$ por um guia referencial $^{20}$ e por uma teoria, ${ }^{21}$ reforçando o aspecto de rubrica.

Outro sítio interessante é Deep Surface, de Stuart Moulthrop, que também tem o mesmo procedimento provocativo - um texto "Reading at risk" proposto em 2004 pelo U.S. National Endowment for the Arts. ${ }^{22}$ Esse material dá margem à construção de um instrumento textual, ou deep reading simulator (simulador de leitura profunda), com o qual o leitor pode e deve interagir em função de sua estratégia particular. Apesar disso, não é possível prever resultados ou estratégias do leitor/fruidor.

\section{(c) classificação orientada}

A terceira proposição é a mais ordeira de todas, por catalogar e direcionar, com prudência e norma o enfrentamento da obra de arte digital. A Electronic Collection Literature tem atualmente três edições (2006, 2011 e 2016), onde a disposição das obras, como construção de acervo, assemelha-se aos princípios da antologia, pela descrição do autor, inserção e contexto de produção. Enquanto propósito, como se aventou, é clássica e contida, até mesmo nas instruções de leitura. Mas não foge ao contexto da rubrica, por explicitar os conteúdos nas palavras-chave. ${ }^{23}$

\section{(d) teoria e crítica}

A mais tensa de todas as rubricas, por seu peso e complexidade, a mescla de obras digitais com textos onde se discute, por exemplo, física e química quân-

\footnotetext{
17 http:/ / libraryofbabel.info/.

18 http:/ / libraryofbabel.info/search.cgi.

${ }^{19}$ http:/ / libraryofbabel.info/About.html.

20 http:/ / libraryofbabel.info/referencehex.html.

${ }^{21}$ http://libraryofbabel.info/theory.html.

22 http:// collection.eliterature.org/2/works/moulthrop_deep_surface/ds/about.htm.

${ }^{23}$ http:// collection.eliterature.org/2/extra/keywords.html.
} 
ticas, programação e modelos matemáticos de alta complexidade (como as equações não-lineares), talvez seja necessária, mas é algo que causa mais do que uma estranheza, uma desfamiliaridade em termos quase absolutos. Esse tipo de experimentação, no qual a PO.EX.net se torna um grande exponencial, coloca o ensino de literatura digital em cama de onze varas, a exigir contextos de formação e de recepção realmente difíceis de encontrar. Muito mais do que o jogo barroco, a poesia simbolista ou as proposições de arte dadaísta e aquela abstrata, esse hibridismo dos objetos literários digitais requer a rubrica, mas fica o usuário/fruidor um tanto descolado e deslocado de sua experiência anterior, reiterando sua apeirokalia. Alguns textos teóricos demonstram o uso dos objetos, teorizando sobre os mesmos, como Virgílio a conduzir um Dante pelos infernos. Como exemplos, podem ser citados Algorritmos: infopoemas (1998), de E. M. de Melo Castro ${ }^{24}$ - do tempo "planográfico" -, e Permuta [Código de programa] (1977), de Pedro Barbosa, ${ }^{25}$ já com uma materialidade digital.

\section{(e) tentativa de não-rubrica}

Por fim, a rubrica mais leve diminui ao máximo a intervenção dos autores sobre o processo de compreensão do objeto digital. Aqui, o exemplo é Palavrador (2006) de Francisco Marinho, conceituador e diretor do projeto, "poema" concebido em workshop durante evento na UFMG, com a participação de vários contribuintes, construído a partir de um objeto de organização de ambiente 3D, com um joystick, caixas de som etc. Na exposição de sua materialidade-coisa, ${ }^{26}$ o diretor afirma que não pode levar o "instrumento" de volta para o Brasil por insuficiência de fundos, a mostrar a portabilidade difícil por questões econômicas e a evanescência da materialidade-função pela impossibilidade de continuado acesso. O poema pode ser explicado por fundamentos, mecânica e instrumentação como suportes de uma experiência também estética. A tentativa de não-rubrica durante a execução ${ }^{27}$ (registro e não experiência estética possível ao fruidor em sala de aula) inibe, talvez, a própria compreensão do objeto palavrador; no vídeo do "funcionamento" do poema, há longa rubrica, sobre a qualidade do objeto digital, descrição lida em inglês, durante a execução do "instrumento".

\footnotetext{
${ }^{24}$ http://po-ex.net/taxonomia/materialidades/planograficas/e-m-de-melo-e-castroalgorritmos.

${ }^{25} \mathrm{http}: / /$ po-ex.net/taxonomia/materialidades/digitais/pedro-barbosa-e-azevedomachado-permuta.

${ }^{26}$ http://youtu.be/OhtOJgmEeEs.

${ }^{27}$ http://collection.eliterature.org/2/works/marinho_palavrador/palavrador.mp4.
} 


\section{Conclusões}

Mesmo que as novas propostas curriculares brasileiras para o ensino médio proponham como relevantes as condições de produção e recepção de textos, ${ }^{28}$ elas primam pela noção do respeito ao patrimônio, evidenciando a manutenção do cânone. Aí vem a questão: como inserir no ensino universitário (e depois na escola básica) os novos meios e, consequentemente, as produções literárias digitais? Enfrentar academicamente a literatura digital mantém o status do noviciado, mesmo que já haja uma produção relativamente longeva. $\mathrm{O}$ interesse flui do assombramento (e resistência) para a ufania, enquanto orgulho da ousadia. Cada vez mais a universidade, e claro com maior amplitude a escola básica, se vê às voltas com essa produção literária digital (que talvez já tenha passado para outra condição, a perder a sua "literariedade" e obtendo um espaço maior - aquele de uma arte multimediática), fazendo com que se problematize o conceito de literatura enquanto arte da palavra. $\mathrm{Na}$ discussão aqui feita, os aspectos da portabilidade dos objetos digitais, da sua evanescência ou fragilidade documental e das rubricas instrumentalizadoras da experiência estética se mostram como os desafios pedagógicos a enfrentar. Quer dizer, não basta mais enfatizar a novidade ou ser instrumental e ideologicamente capaz de lidar com tais objetos. É necessária uma consciencialização que precisa partir dos desafios advindos de tal incorporação dos novos objetos.

Nesse ponto, preocupa-me enfatizar junto a meus alunos a necessidade premente de abertura de horizontes, para entender os objetos digitais, e do estudo da literatura não para negar a produção literária "tradicional", mas, também e principalmente, para participar da compreensão do próprio substrato do "literário" como propôs Hayles. A hibridização da arte digital é inevitável e não há, parece, mais necessidade de temer a inexistência do livro em papel em futuro próximo. Em verdade, sabemos muito pouco sobre nós leitores e sobre as possibilidades criativas. A escola precisa lidar com a contemporaneidade, mais do que anunciá-la como postura libertária, enfrentando-a com a humildade necessária de quem pela primeira vez compreendeu que a morte podia acontecer. Talvez esse seja o nosso maior desafio, aceitarmos que há muito mais em nós do que sonhávamos e que a arte se faz por ser arte, incontida, imersa em si mesma como redemoinho, a despertar desde antes a emoção que já conhecíamos.

\footnotetext{
28 Analisar, interpretar e aplicar os recursos expressivos das linguagens, relacionando textos com seus contextos, mediante a natureza, função, organização, estrutura das manifestações, de acordo com as condições de produção e recepção (intenção, época, local, interlocutores participantes da criação e propagação de ideias e escolhas, tecnologias disponíveis etc). (BRASIL, PCNEM: 72; disponível em http://portal.mec.gov.br/seb/arquivos/pdf/linguagens02.pdf).
} 


\section{Referências $^{29}$}

ATTIAH, Karen (2015). "How Western media would cover Baltimore if it happened elsewhere." Washington Post 30 abr.

http://www.washingtonpost.com/blogs/post-

partisan/wp/2015/04/30/how-western-media-would-cover-baltimore-

if-it-happened-elsewhere/?postshare $=401430447574070$.

BAGGI, Cristiane Aparecida dos Santos, Doraci Alves Lopes (2011). "Evasão e avaliação institucional no ensino superior: uma discussão bibliográfica." Avaliação 16.2 (jul.): 355-374.

http://www.scielo.br/pdf/aval/v16n2/a07v16n2.

BAKHTIN, Mikhail (2002). Questões de Literatura e Estética. São Paulo: Hucitec.

BENNETT, Sue, Karl Maton, Lisa Kervin (2008). “The 'digital natives' debate: a critical review of evidence." British Journal of Educational Technology 39.5: 775-786. doi:10.1111/j.1467-8535.2007.00793.x.

BOLTER, Jay David (2007). "Digital Media and Art: Always Already Complicit?” Criticism 49.1 (winter): 107-118.

http://digitalcommons.wayne.edu/criticism/ vol49/iss1/5.

BOLTER, Jay David, and Richard Grusin (1999). Remediation: Understanding New Media. Cambridge: MIT Press.

CAMPOS, Augusto (2003). Não: Poemas. São Paulo: Perspectiva.

COLLINS, Jim (2010). Bring on the Books for Everybody: How Literary Culture Became Popular Culture. Durham: Duke University Press.

CORRÊA, Alamir Aquino (2012). "Is Jorge Amado the gateway to Brazil or not?” Comparative Literature Studies 49.3: 361-371.

http://www.jstor.org/stable/10.5325/complitstudies.49.3.0361.

(2014). "Aspectos Antitéticos entre Apeirokalia e Liberdade Criadora na Arte Digital.” Criação Digital: Prática e Reflexão. Eds. Cláudia G. Vilarouca, Otávio G. Tavares e Cláudio A. C. Moura. Florianópolis: Copiart. 46-58.

(2016). “Tecnología y la poesía en Brasil: lo visual, lo sonoro y el nuevo 'bello' posible." Poesía y Poéticas digitales / Electrónicas / Tecnos / New-media en América Latina: Definiciones y Exploraciones. Eds. Luis CorreaDíaz e Scott Weintraub. Bogotá: Universidad Central. 637-664. http://www.ucentral.edu.co/editorial/catalogo/poesia-poeticas-digitales.

EARHART, Amy E. (2012). "Can Information Be Unfettered? Race and the New Digital Humanities Canon." Debates in the Digital Humanities. Ed. Matthew K. Gold. Minneapolis: University of Minnesota Press. 309-318. FUNKHOUSER, Christopher (2007). Prehistoric Digital Poetry an Archaeology of Forms. Tuscaloosa, AL: University of Alabama Press.

${ }^{29}$ NB: todas as referências em linha foram visitadas em 26 de fevereiro de 2016. 
(2008). "Digital Poetry: A Look at Generative, Visual, and Interconnected Possibilities in its First Four Decades." A Companion to Digital Literary Studies. Eds. Susan Schreibman e Ray Siemens. Oxford: Blackwell. http://www.digitalhumanities.org/companionDLS/. (2012). New Directions in Digital Poetry. New York: Continuum.

GARCÍA CANCLINI, Néstor (1989). Culturas Hibridas: Estrategias para Entrar y Salir de la Modernidad. México: Grijalbo. (2004). Diferentes, Desiguales y Desconectados. Barcelona: Gedisa.

GIAMPÁ, Daniele (2010). Testo e Tessuto. Parla come Navighi. Antologia della Webletteratura Italiana. Ed. Mario Gerosa. Piombino: Associazone Culturale Il Foglio. http://elmcip.net/node/10384.

HARTLING, Florian (2005). "The Canonization of German-language Digital Literature." CLCWeb: Comparative Literature and Culture 7.4 http://dx.doi.org/10.7771/1481-4374.1281.

HAYLES, N. Katherine (2008). Electronic Literature: New Horizons for the Literary. Notre Dame: University of Notre Dame Press.

JONES, Christopher, Binhui Shao (2011). The Net Generation and Digital Natives: Implications for Higher Education. York: Higher Education Academy. https://www.heacademy.ac.uk/node/4011.

JUVAN, Marco (2000). "On Literariness: From Post-Structuralism to Systems Theory." CLCWeb: Comparative Literature and Culture 2.2.

http://docs.lib.purdue.edu/clcweb/vol2/iss2/.

KIRCHOF, Edgar R. (2013). "Desafios para o ensino da literatura digital." Revista da ANPOLL 35: 127-142.

http://www.anpoll.org.br/revista/index.php/revista/article/view/647/ 716.

KIRSCHENBAUM, Matthew G. (2008). Mechanisms: New Media and the Forensic Imagination. Cambridge, MA: MIT Press.

KNEWTON. Flipped classroom. http://www.knewton.com/flipped-classroom/.

LANDOW, George P. (2006). Hypertext 3.0: Critical Theory and New Media in an Era of Globalization. Baltimore: Johns Hopkins University Press.

LAVAGNINO, John (2008). "Digital and Analog Texts. A Companion to Digital Literary Studies." Eds. Susan Schreibman e Ray Siemens. Oxford: Blackwell. http://www.digitalhumanities.org/companionDLS/.

PAYNE, Susan E. (2013). "Teaching Today's "Digital Native" College Student." North American Professors of Christian Education Conference: papers. http://www.napce.org/documents/!pdfs/papers-2013/payne.pdf.

PRENSKY, Marc (2001). "Digital Natives, Digital Immigrants Part 1." On the Horizon 9.5: 1-6. http://dx.doi.org/ 10.1108/10748120110424816.

(2010). Teaching Digital Natives: Partnering for Real Learning. Thousand Oaks: Corwin.

PRESSMAN, Jessica (2014). Digital Modernism: Making it New in New Media. New York: Oxford U P. 
PRESSMAN, Jessica, and Lisa Swanstrom (2013). "The Literary And/As the Digital Humanities.” Digital Humanities Quaterly 7.1.

http://www.digitalhumanities.org/dhq/vol/7/1/000154/000154.html.

PRICE, Kenneth M., and Ray Siemens (2014). "Introduction.” Literary Studies in the Digital Age: An Evolving Anthology.

https://dlsanthology.commons.mla.org/introduction/.

RETTBERG, Scott (2013). "An Emerging Canon? A Preliminary Analysis of All References to Creative Works in Critical Writing Documented in the ELMCIP Electronic Literature Knowledge Base." Elmcip.

http:/ / elmcip.net/criticalwriting/emerging-canon-preliminary-analysisall-references-creative-works-critical-writing.

RONSON, Jon (2015). "How One Stupid Tweet Blew Up Justine Sacco's Life." The New York Times Magazine $12 \mathrm{fev}$.

http://www.nytimes.com/2015/02/15/magazine/how-one-stupidtweet-ruined-justine-saccos-life.html?_r $=0$.

SANTOS, Alckmar Luiz dos (2003). Leituras de Nós: Ciberespaço e Literatura. São Paulo: Itaú Cultural.

SANZ, Amelia (2013). "Digital Humanities or Hypercolonial Studies." http://responsibleinnovation.org.uk/torrii/sites/default/files/Final\%20_sanz_hypercolonial_sent3 .pdf.

SCHOLES, Robert (1985). Textual Power: Literary Theory and the Teaching of English. New Haven: Yale University Press.

SIMANOWSKI, Roberto, Jörgen Schäffer, Peter Gendolla (2010). Reading Moving Letters: Digital Literature in Research and Teaching. New Brunswick: Transcript.

SMITH, Erika (2013). "Are Adult Educators and Learners 'Digital Immigrants'? Examining the Evidence and Impacts for Continuing Education." Canadian Journal of University Continuing Education 39.1 (spring): 1-13. https://ejournals.library.ualberta.ca/index.php/cjucercepu/article/viewFile/20722/15827.

STOKES, Suzanne (2001). "Visual Literacy in Teaching and Learning: A Literature Perspective." Electronic Journal for the Integration of Technology in Education 1.1. http://ejite.isu.edu/Volume1No1/Stokes.html.

TWEEDIE, Eddie (2015). "Google's New Classroom App Lets Kids Turn In Homework With Their Phones.” Business Insider. http://www.businessinsider.com/google-classroom-app-lets-kids-turnin-homework-with-their-phones-2015-1.

UNESCO. Institute for Information Technologies in Education (2011). Policy Brief - Digital Natives: How do They Learn? How to Teach Them? http://iite.unesco.org/pics/publications/en/files/3214698.pdf.

WOODALL, Stephen (2014). "Radical Publishing: The Organization and Distribution of Art, Literature and Information in the 21st Century." 
Eds. Dennis Reidsma, Insook Choi e Robin Bargar. Intelligent Technologies for Interactive Entertainment. Cham: Springer. 123-127.

YOO, Hyun-Joo (2007). Text, Hypertext, Hypermedia. Ästhetische Möglichkeiten der digitalen Literatur mittels Intertextualität, Interaktivität und Intermedialität. Würzburg: Königshausen \& Neumann.

(C) 2016 Alamir Aquino Corrêa.

Licensed under the Creative Commons Attribution-NoncommercialNo Derivative Works 4.0 International (CC BY-NC-ND 4.0). 